\title{
El neo-liberalismo una negación del liberalismo.
}

\author{
Luis de Sebastian
}

\section{Introducción}

La tesis que defiendo en este articulo es que el fenómeno social e ideológico conocido en nuestro tiempo como neo-liberalismo no se parece en nada al liberalismo económico clásico de los autores de la Economía Política Británica de los siglos XVIII y XIX. Antes bien es un movimiento opuesto a los ideales, motivaciones y objetivos económicos y sociales que tuvo aquel. El término neo, añadido al de liberalismo, resulta de hecho equivalente a no-liberalismo.

Para mi el neo-liberalismo es no-liberalismo; es la negación del liberalismo. Esto to voy a demostrar, mostrando que la ideologia "neoliberal" de nuestra época es darwinismo social, la doctrina que exalta la necesidad y conveniencia para el conjunto de la sociedad (y de la especie humana) de que algunos miembros de ella, los mejor dotados y capacitados para la competencia económica, tengan todas las oportunidades de triunfar y sobrevivir en el enfrentamiento de los hombres contra la naturaleza y de los hombres entre si por mantener el control sobre los recursos creadores de riqueza.

Por su propia descripción se hará evidente que el darwinismo social es conceptualmente contradiclorio y prácticamente incompatible con los valores que promovía o intentaba promover el liberalismo tradicional.

2. el liberalismo como movimiento de oposición a los monopolios reales

\subsection{La oposición social al "Ancien Régime"}

El liberalismo como movimiento social es un movimiento de oposición 
al modo de concebir y organizar la sociedad que resulta de la evolución del mundo medieval hacia el mundo de los estados-nación centralizados y regidos por monarquías absolutas.

Tanto en el medievo como en la edad moderna se mantiene la concepción de que la sociedad está formada por personas, situadas por nacimiento en estados $\longrightarrow$ estamentos- sociales, subordinados unos a otros bajo la autoridad real. Los "estados" son inmutables, infranqueables y estancos (es decir, que no se puede pasar de uno a otro), como reflejo del destino de las personas en la historia, que les ha asignado Dios. Y de hecho la movilidad social es normalmente rara e imperfecta. solo se llega a las cimas de la sociedad o por el heroísmo en las guerras, o por la conquista de nuevas tierras en ultramar o por la santidad en la religión (el ejército y la iglesia son los únicos canales institucionalizados de movilidad social). El comercio y las finanzas son ciertamente caminos de riqueza, pero no necesariamente de ascensión social, aunque, a la larga, la Providencia siempie encontraba la manera de transformar la riqueza en nobleza.

Esta concepción de la sociedad sanciona la desigualdad en el estado de las personas, $y$, por consiguiente, en sus prerrogativas y derechos, como una manifestación de una voluntad divina misteriosa y soberanamente arbitraria. La igualdad radical de la condición de hijos de Dios y redimidos por la sangre de Cristo, que se defiende en Teologia, no tiene su reflejo o correlato social en una igualdad básica de todos los seres humanos en las actividades e instituciones de la vida social.

Antes, al contrario, el ordenamiento jerárquico de los "estados" es un requisito para el buen funcionamiento de la sociedad y para la mayor gloria de Dios'.

El poder político, o sea, el poder real viene directamente de Dios, aunque esta voluntad de Dios a veces habia que descubrirla, a posteriori, en el éxito de guerras, conspiraciones o conquistas. Normalmente esta voluntad se manifestaba a través de la sucesión dinástica. El pueblo no tiene en sí ningún poder, ni sus derechos son originarios; solo tiene los derechos que le concede el rey. El pueblo se beneficia del poder real en la medida en que es buen súbdito, cumpliendo sus obligaciones para con el rey, que es quien se debe encargar de procurar el bienestar de todos sus súbditos.

\subsection{La "economía sometida" en el régimen de monarquía asboluta}

En este estado de cosas, el ordenamiento, vigilancia y control de la economia es una de las principales prerrogativas y responsabilidades 
del rey. Desde tiempos inmemoriales se ha creido en la necesidad de ordenar y regular el ejercicio de las actividades comerciales y cambiarlas $^{2}$. También desde la más remota antigüedad se ha reconocido a los gobernantes el derecho de cobrar impuestos y de incurrir en una serie de gastos necesarios para la comunidad.

Durante muchos siglos la actividad económica ha estado regulada "desde fuera", bien por principios religiosos (como la obligación de pagar diezmos y primicias, la prohibición de la usura, etc.) o por principios políticos ("el comercio intemacional es una prolongación de la diplomacia y aun de la guerra") o por otro tipo de consideraciones, como el arbitrario y el capricho real. Esta práctica correspondia al estado de opinión dominante. Hasta muy recientemente en la historia de la humanidad, la actividad económica de los particulares se ha considerado incapaz de contribuir a los objetivos comunes de la sociedad (supremacia politica, triunfo militar o el "bien común"), si no se ordenaba y se sometía a los conceptos y designios rectores de la autoridad. EI egoísmo se concebía como socialmente ineficiente y la autonomía de los agentes económicos como una debilidad o responsabilidad de los poderes públicos.

En la monarquía absoluta, además, la actividad económica está sometida a la corona en la medida en que crea riqueza y la riqueza es fuente de poder. La riqueza de las arcas reales hace posible las flotas y los ejércitos, los cahones y las fortificaciones. Hace posible también dotes matrimoniales y la compra de estadistas extranjeros. No se puede, pues, dejar la creación de la riqueza-poder (nacional e internacional) al azar, a la improvisación 0 al arbitrio de múltiples agentes económicos, cuando cada cual busca su propio provecho y no el del estado, o sea el de la corona. Esta es la concepción básica - derivada, por cierto, de Maquiavelo- de lo que autores posteriores y críticos llamarian el mercantilismo. Contra esta concepción se rebelan los economistas liberales del siglo XVIII y XIX.

El mercantilismo o sistema mercantil, como lo calificó Adam Smith ${ }^{3}$, representa la máxima expresión del control estatal de una economia nacional cada vez más compleja y amplia. Los autores liberales pusieron sus puntos de mira en la organización de la economía francesa durante los últimos Borbones - concretamente bajo el ministro Colbertcomo el prototitpo de una organización absurda y aberrante económicamente, que un estado moderno tendría que evitar a toda costa.

El mercantilismo, en esencia, prescribe hacia afuera una politica comercial agresiva y proteccionsita, con vistas a maximizar el saldo de la balanza de pagos y el consiguiente flujo de oro y plata (la "especie", 
como decian entonces); y hacia adentro el control y la "planificación"4 de la economia, con vistas a servir más eficientemente a los intereses políticos de la corona. Para ello, a lo largo de los siglos XVI y XVII, se puso en pie una organización basada en los monopolios reales: grandes empresas, que, bajo la protección especial de la corona y con exclusión de competidores, se dedicaban a las actividades comerciales y productivas de los reyes juzgaban de mayor trascendencia para sus proyectos.

De esta manera, el gran comercio, el comercio en los nuevos y fascinantes productos ultramarinos, la producción que aplicaba nuevas tecnologías, y algunas actividades agricolas esenciales, se desarrollaron bajo un régimen de protección y monopolio, que proporcionó grandes ganancias a los beneficiarios, pero que implicaba a la vez gran control e interferencia por parte de los gobernantes y ministros de finanzas. A larga, de este régimen económico resultaron grandes ineficiencias y distorsiones en los mercados, con severos daños para la multitud de pequeños comerciantes y agricultores no protegidos, así como para la clase emergente de fabricantes independientes, que dejando los gremios, comenzaron a producir (por su cuenta y con una "división del trabajo") las manufacturas de uso más corriente.

\subsection{Las fuerzas liberadoras del mercado. La auto-regulación}

La manera de liberar a la actividad económica de la tutela y control real comienza por demostrar que esta tutela no es necesaria, sino, más bien, contrasproducente. Esta novedosa y difícil demostracióbn supone una especie de armonía pre-establecida en el terreno económico, en virtud de la cual, mientras cada empresario emplea los recursos productivos de la manera más ventajosa para él, se produce una asignación de recursos más ventajosa para la comunidad.

Gestionando esa industria de manera que su producto sea del mayor valor posible, el (empresario) busca únicamente su propio beneficio, y en esto, como en muchos otros casos, está derigido por una mano invisible a lograr un fin que no era parte de su intención. ${ }^{5}$.

El liberalismo supone también el sometimiento de los mercados y de las relaciones económicas entre los agentes a unas leyes de funcionamiento, tan objetivas como las leyes físico-naturales, que delimitan las posibilidades de lo que puede hacerse desde fuera con el sistema económico. Estas leyes tienen que ser conocidas como condicionantes de actuar, respetadas como normas y utilizadas para predecir los resultados de la actividad económica. Ellas ofrecen las líneas de movimiento más seguras para lograr que el sistema funcione bien. Lo mejor 
que se puede hacer con la economía es dejar que las leyes objetivas que la rigen funcionen solas, sin interferencias externas.

Con otras palabras el sistema económico (es decir, el conjunto de mercados de productos y factores de producción) se puede regular a si mismo. Pero para ello es necesario que las autoridades no impidan, con su intervencionismo, que funcione el mecanismo de auto-regulación. De ahi la exigencia del laissez faire, laisez passer ("dejar que las cosas sigan su curso natural"). La pieza clave del mecanismo de autoregulación es la competencia entre compradores, tanto de productos, como de los servicios de los factores de producción. La competencia, basada en una buena información sobre las posibilidades que ofrecen los mercados, es en definitiva la fuerza social que equilibra los mercados, igualando la oferta y la demanda.

El equilibrio de los mercados determina unos precios que reflejan perfectamente tanto las preferencias subjetivas de los consumidores, como las disponibilidades objetivas de los productores. De esta manera, no solo se obtiene la mejor (para la sociedad) asignación posible de los recursos productivos, sino que se obtienen los mejores precios posibles, es decir los precios más bajos y más ajustados a las condiciones de producción. Los precios de equilibrio, o precios competitivos, resultan ser, en cierta manera, los precios justos que tanto preocupaban a los predicadores y moralistas de los siglos anteriores.

\subsection{La competencia como la energía generadora de la eficiencia social}

Para los liberales clásicos, la competencia era una cosa muy seria. En su esquema, no hay más lazo de unión entre los esfuerzos individuales de muchos agentes económicos que actúan egoistamente y el bien de la sociedad, el cual también les interesa, que el de la competencia. La competencia liga a los individuos, aun a pesar suyo, y les condiciona para que de todas las opciones posibles escojan de hecho, como por imposición del conjunto de agentes sobre cada uno en particular, las que son mejores para el conjunto. Así el conflicto entre el individualismo-egoísmo y el bien común, se resuelve por la acción de la competencia sobre las decisiones individuales. Si se eliminara la competencia del sistema económico, desapareceria el vínculo entre el interés individual y el bien común. Sin competencia resultaria una sociedad donde domina la ley del más fuerte, donde los intereses particulares de los que han encadenado las fuerzas de la competencia (los monopolios) dominan sobre los intereses generales. En esta sociedad no habrían igualdad de oportunidades, ni libertad económica, ni 
eficiencia social. Es una sociedad que los liberales clásicos rechazarian como una reproducción de las peores instituciones del pasado que ellos trataron de eliminar.

\subsection{El monopollo como negación radical de la competencla y del mecanismo auto-regulador}

La existencia de la competencia supone pues una organización económica en que ninguno de los empresairos o agentes participantes posee una desmesurada cuota de poder sobre el mercado. Todos tienen que ser pequeños empresairos - para usar terminología moderna-, o por lo menos, empresarios con aproximadamente las mismas oportunidades: el mismo acceso a las materias primas y la tecnología productiva, el mismo acceso a los mercados de los productos, la misma información sobre las preferencias y demandas de los consumidores, etc. En cuanto alguna empresa tenga alguna clara ventaja sobre las demás en alguno de estos aspectos se impondrá sobre las demás y la competencia entre ellas se verá disminuida. Este es, en realidad, un mundo de igualdad de oportunidades para los agentes económicos, basado en igual información e iguales condiciones, donde sólo diferencia el mayor trabajo, la mayor comprensión de las leyes del mercado, o la suerte.

Estas condiciones no se daban en el sistema mercantilista, que se basaba en la existencia de monopolios reales. La regulación, hecha al margen, (o en contra), de las leyes objetivas del mercado era necesariamente ineficaz. Los recursos no se empleaban de la mejor manera posible ni los precios resultantes de la intervención real eran los más justos (más bajos).

Adam Smith lo tenia muy claro

El monopolio, además, es un gran enemigo de la buena gestión, que no se puede establecer universalmente si no es como consecuencia de una competencia libre y general que obliga a cada cual a recurrir a ella para su propia defensa. ${ }^{6}$

Y John Suart Mill también:

Yo pienso que, incluso en el estado actual de la sociedad y de la industria, toda restricción de la competencia es un mal y toda extensión de ella, aun cuando por algún tiempo perjudique a alguna clase de trabajadores, es siempre un bien definitivo. ${ }^{7}$

David Ricardo, por su parte, atacó severamente los monopolios en el comercio internacional, como ineficientes y perjudiciales a la larga contra el pais que los establece. ${ }^{8}$ 

Morales"

Sería injusto atribuir a los liberales tradicionales una concepción del mundo puramente armonicista" (creencia en la armonia pre-establecida de los intereses económicos de las diferentes clases). Según ha resaltado el historiador del Pensamiento Económico, $X_{\text {Lionel Robbins, }-y}$ como se ve leyendo sus obras-, los clásicos liberales estaban muy conscientes de los conflictos de intereses que se podian dar entre las diversas clases sociales: $X$

Aun concediendo la posibilidad de establecer un estado de perfecta libertad económica... la armonía que se establecería sería una armonia de una naturaleza muy limitada. Habria ventajas mutuas en el intercambio... Pero las tendenciass a largo plazo de la sociedad no eran necesariamente buenas ni se armonizaban los intereses de todos. Los analistas clásicos abundan en descripciones pesimistas y revelaciones de los conflictos de intereses. ${ }^{9}$

En' efecto, en ellos encontramos descripciones perfectas de lo que Marx, años más tarde, habria de llamar la "lucha de clases". Bástenos aquí recordar el capítulo octavo del libro primero de La Riqueza de las Naciones, "sobre los salarios del trabajo", donde se describe perfectamente los conflictos y los juegos de poder que entran en la determinación de los salarios.

En los clásicos, pues, la competencia, para resultar una energía ordenadora de los intercambios económicos, tenía que inscribirse en un ordenamiento jurídico, que limitaba los derechos de cada uno con los iguales derechos de los demás, y practicarse desde una actitud ética, que tuviera en cuenta las consecuencias sobre los demás miembros de la sociedad de las propias acciones en busca del bien particular. De esta manera, la competencia no chocaba con la democracia, ni con la igualdad ante la ley de todos los ciudadanos, ni contra la libertad de todos en el mercado. Los principios y comportamientos económicos exaltados en "La Riqueza de las Naciones" están enmarcados en los principios morales de la "Teoría de los Sentimientos Morales", la otra gran obra de Adam Smith.

Asi concebida, la competencia no es solamente una garantia de eficiencia en la asignación de los recursos escasos, sino también una defensa de la libertad económica individual y de la igualdad de oportunidades en el mercado. Es, sin duda, una competencia utópica; pero no se negará que es compatible con los ideales revolucionarios de libertad, igualdad y fraternidad (aunque esto último menos claramente!) 
La concepción ética que subyace a la noción clásica de la competencia se delata en la preocupación de los economistas clásicos por "the condition of the people" (la suerte de las gentes) o el problema social, que la revolución industrial estaba generando ante sus ojos. Así, Adam Simith opinaba:

Los sirvientes, obreros y trabajadores de diversas clases componen con mucho la mayoría de toda sociedad política desarrollada. Pero lo que mejora las condiciones de la mayoría nunca puede considerarse como un inconveniente para el conjunto. Ninguna sociedad puede ser floreciente y feliz, si la mayoría de sus miembros son pobres y miserables. ${ }^{10}$

Y Robert Malthus años después afirmaba:

Si un pais solo puede ser rico por medio de una carrera de salarios bajos , yo estaría dispuesto a decir: abajo con esa riqueza. ${ }^{11}$

Autores posteriores perderían este interés por la suerte de las mayorías, al plantear el problema de la redistribución, no como el problema de repartir el "producto anual entre las diversas clases de gente" (David Ricardo), sino como el problema de poner precio a unos factores de producción, concebidos como cantidades in abstracto (prescindiendo de la cuestión de quien los ha apropiado) de diversos recursos productivos que entran en una función objetiva de producción. La diferencia con los clásicos de la segunda generación, o marginalistas, es tremenda, y marca la diferencia entre una concepción de la competencia con limitaciones y preocupaciones éticas y otra sin este tipo de preocupaciones. Los clásicos de primera hora aparecen en la historia como unos reformadores humanistas y éticos, aunque algo ingenuos, que fueron opacados pronto por oportunistas, apologistas y defensores a ultranza del "statu quo". De estos tenemos que ocuparnos con más detenimiento.

\section{La revolución industrial y la realización concreta de los Ideales liberales}

\subsection{La tendencia a la concentración de las empresas}

La utilidad social del liberalismo clásico, como conjunto de principios para ordenar la actividad económica, se va agotando a medida que va desapareciendo el capitalismo competitivo de primera hora. Las muchas empresas de proporciones aproximadamente iguales pasan por un proceso de concentración que reduce su número. Asi comienzan a aparecer empresas grandes, monopolios y oligopolios, que gradualmente van a cambiar la estructura de los principales mercados. Las condi- 
ciones de posibidad para la libre competencia entre agentes económicos en los sectores más dinámicos han dejado de existir como realidad histórica ya a finales del siglo $X \mid X$. Lo que se va a seguir llamando "competencia" es otra fuerza social, un fenómeno de naturaleza distinta, Es básicamente un conjunto de reglas de juego (o de comportamiento) de las grandes empresas, para repartirse unos mercados en expansión sin amenazarse y destruirse mutamente. El talante ético de esta nueva clase de competencia brilla, naturalmente, por su ausencia.

Karl Marx había visto con gran clarividencia en los albores de la Revolución Industrial que la tendencia a la concentración de emrpesas en conglomerados mayores es algo conatural a los mercados capitalistas. La "explotación de capitalistas por capitalistas", como diría este autor, lleva necesariamente a destruir las condiciones de la competencia "idílica" y ética en que se basan las concepciones liberales clásicas. La necesidad de crecer, la aparición desigual de "economias de escala" y externalidades en los procesos productivos, las ambiciones personales y otros factores rompen pronto las filas de las empresas que compiten en pie de igualdad. Alguna crece más rápidamente que las otras y se apodera de porciones mayores del mercado. Las demás desaparecen, engullidas por la primera o han de asociarse a su vez en una empresa mayor para poder hacerle frente. La innovación tecnológica también va ofreciendo ventajas a algunas empresas que se constituyen en las dominantes de sus mercados.

De esta manera se van estableciendo los monopolios en los mercados competitivos. Sólo que ahora no son monopolios regios o estatales, (como los mercantilistas que fueron combatidos por los liberales), sino monopolios privados, con una fuerza que llega a enfrentarse - a dominar el poder de los monarcas y gobernantes. Pero pocos son los verdaderos monopolios, es decir, aquellos en que una industria se reduce a una empresa (como fue la Tabacalera en España, durante muchos años). Normalmente los mercados se los reparte un número reducido de empresas (cuatro empresas en el automívil en Estados Unidos, por ejemplo), que compiten entre si dentro de un acuerdo tácito o explicito, cuando la ley no lo prohibe, para no perjudicarse en cosas esenciales.

La base factual y la realidad empresarial, en que se sustentaba el modelo liberal de ordenamiento económico habia cambiado radicalmente. Pero se seguia usando el paradigma liberal para contener la intervención del Estado contra los abusos de los monopolios; se seguia usando la imagineria de un mundo de pequeñas o medianas empresas competitivas aplicandola a os problemas e intereses de las grandes 
empresas en una estructura oligopolista. ¿Porque se procedió así? Quizá por que los economistas no pudieron encontrar una teoria que justificara la eficiencia social de la nueva organización de los mercados; quizá por que los empresarios comprendieron que las ideas antiguas y ya anacrónicas - rendian un servicio de ocultamiento, y por lo tanto de defensa, de los poderes que las grandes empresass ejercian indebidamente sobre la sociedad. ${ }^{12}$

* Los clásicos de segunda ola, los neo-clásicos, quitaron los aspectos desagradables de la economía clásica como la teoría de la distribución ("la funesta oposiciónentre los salarios y los beneficios"), y elaboraron con derroche de agudeza mental el modelo de equilibrio general de competencia perfecta, en la medida en que la competencia generalizada desaparecia y se transformaba a lo más en competencia monopolista. Solo en. los años anteriores a la II Guerra Mundial se comenzó a escribir, no sin cierta timidez, sobre la "competencia imperfecta" como un modelo alternativo al estudio de los mercados.

\subsection{La Revolución Industrial en Inglaterra y Estados Unidos}

Es interesante compararlas, por que se dieron en circunstancias y con modalidades distintas, $y$ - 0 que es más relevante para nuestro argumento- porque el pensamiento subyacente también fue muy diverso. La revolución industrial inglesa es el fenómeno de fondo del capitalismo originario, competitivo, de pequeñas y medianas empresas, que trabajaban el textil y los metales. Constituye el "Sitz en Leben" del liberalismo clásico.

La revolución industrial en Estados Unidos comenzó más tarde, logrando su apogeo con la construcción del ferrocarril entre 1867 y 1890. En este proceso, las empresas pequeñas y medianas no tuvieron el mismo protagonismo que en Inglaterra. En USA las grandes empresas oligopolistas fueron desde el principio los impulsores de la construcción y explotación de los ferrocarriles, el verdadero polo de desarrollo de la economía norteamericana. Fueron también grandes empresas las que desarrollaron la industria del acero, de la extracción y refinado del petróleo, del carbón, del tabaco, de la madera, del automovil, etc. La revolución industrial americana está protagonizada por los "big business" y los grandes empresarios como Vanderbilt, Rockefeller, Carnegie. Duke, Stanford, Morgan, etc. personas que acumularon muy rápidamente un inmenso poder, tanto en el sector financiero como en el sector real.

En ese contexto socio-económico no había lugar para el liberalismo competitivo-humanista de Adam Smith, Malthus y Stuart Mill. En Estados 
Unidos, de hecho no hubo una ideología liberal aplicada a los negocios, aunque la revolución americana estaba inspirada fuertemente por los liberales europeos de la época. No es coincidencia que el año de su independencia sea el año de publicación de "La Riqueza de las Naciones". Pero, según la mayoría de los historiadores, el desarrollo económico que tuvo lugar en la segunda mitad del siglo XIX poco tenía en común con los ideales de Washington, Jackson y los demás padres de la patria, que contemplaban como típicamente americana una sociedad de pequeños y medianos empresarios mayoritariamente rurales que trabajaban en un mundo donde reinaba la igualdad de oportunidades. El inmenso poder que amasaron los banqueros, ferroviarios e industrialistas trastocó los ideales que animaban a la mayoria de la población americana todavia rural, y provocó muchas protestas y aun revueltas políticas contra el poder de los multimillonarios. Estos se sirvieron descaradamente de la administración pública para aumentar las ocasiones de enriquecerse y evitar las regulaciones y trabas a sus manejos, aunque el desastre de los años treinta acabó por hacerlas inevitables.

Los grandes "tycoons" no tenian más ideología que la de acumular poder y dinero. Algunos se sirvieron de la ideología liberal, aunque tardíamente y con no mucha convicción, para justificar la ausencia del gobierno federal en el mundo de los negocios y para rechazar sus intervenciones, siempre tímidas e insuficientes, destinadas a limitar el poder y los abusos de los grandes empresarios. En este vacio ideológico, sin embargo, prosperaron las nociones y conceptos de Herbert Spencer, un profesor escocés llevado a Estados Unidos por Andew Carnegie, el rey del acero, (también escocés de origen), para difundir sus creencias entre el público americano. Spencer es el padre del darwinismo social, que, para ponerlo en dos palabras, defiende el privilegio de los más fuertes como un requisito para el bien de toda la sociedad.

Un aprovechado discipulo de Spencer, el profesor William Graham Sumner, escribia en marzo de 1894:

El movimiento de organización industrial que acabamos de describir ha producido una gran demanda de hombres capaces de gestionar grandes empresas. A estos se les ha llamado "capitanes de la industria"... Los grandes líderes del desarrollo de la organización industrial necesitan los talentos de habilidad administrativa y ejecutiva, poder para mandar, coraje y fortaleza, que antes sólo se requerian en los asuntos militares... La posesión de las cualidades requeridas es un monopolio natural. En consecuencia, todas las circunstancias han concurrido en dar a los que poseen este monopolio 
enormes y siempre crecientes niveles de remuneración... Los capitanes de la industria y los capitalistas que operan sobre la coyuntura, ganan, si tienen éxito, grandes fortunas en un tiempo muy breve. No hay ganancias que sean más legítimas ni que rindan mayor servicio al conjunto del cuerpo industrial... Sería fácil mostrar que se hace bien con la acumulación de capital en pocas manos, es decir, bajo una estrecha y directa gestión, permitiendo una pronta y acertada aplicación. Como seria fácil decir que se hace daño con acusaciones vagas e infundadas de elementos y grupos sociales determinados. En los recientes debates acerca del impuesto sobre la renta, se ha tratado como un axioma que las grandes acumulaciones de riqueza son socialmente perjudiciales y tendrian que romperse con impuestos. Tenemos pruebas directas de cuan dañoso es equipar a los políticos y periodistas con estos dogmas que no han sido demostrados porque son indemostrables...13

$Y$ el promotor americano de Herbert Spencer, Andrew Carnegie escribia a finales del siglo XIX acerca de una situación ideal

en que los excedentes de riqueza de los pocos se convertirian, en el mejor sentido de la plalabra, en propiedad de los muchos, porque se administrarian para el bien común; y esta riqueza, pasando por las manos de los pocos, seria una fuerza para la elevación de nuestra raza mucho más potente que si se distribuyera en pequeñas sumas entre las gentes del pueblo. Aun los más pobres tienen que ver este argumento y estar de acuerdo en que las grandes sumas acumuladas por unos pocos de sus conciudadanos y gastadas en objetivos sociales, de los que las masas sacan también beneficios, les son más valiosas que si estuvieran dispersas a través de los años en cantidades pequeñas. ${ }^{14}$

El argumento es realmente increible: la concentración es mejor que la redistribución, aun para los más pobres!! Aqui el liberalismo económico está totalmente superado por la ley del más fuerte o "the survival of the fittest", que impulsa la evolución de las especies animales, según Darwin. Esto es lo que entendemos por darwinismo social.

Esta es la verdadera filosofía social del capitalismo de los oligopolios. Lo que sucedió es que no se pudo seguir defendiendo en la forma descarnada de Spencer, Sumner y Carnegie. La crítica sistemática de los abusos de los "big busines" en Estados Unidos por parte de escritores, predicadores y algunos políticos más honrados, obligó a los hombres de empresa a buscar la manera de ocultar lo que tanto irritaba a la opinión pública: la extraordinaria acumulación de dinero y de poder en pocas manos. Para eso servian admirablemente los modelos de 
competencia perfecta que glorificaban las excelencias de un mercado abstracto, el cual, por cierto, en nada se parecía a la realidad de la organización industrial imperante ya a finales del siglo XIX.

En Europa, el fortalecimiento de los sindicatos y de los partidos socialistas obligó también al capital de los oligopolios a renunciar a la defensa abierta de un sistema social basado en la concentración de riqueza en relativamente pocas personas. Aquí también trató de encubrirse la realidad con el desarrollo de una teoria abstracta que prescindia totalmente de la cuestión de la apropiación de los factores productivos y reducía los problemas de la distribución del ingreso a la tijación de los precios de unos factores abstractos.

\subsection{La ideologia de la economía mixta}

La Gran Depresión de los años trienta, con sus secuelas de quiebras de muchos negocios, desempleo y pobreza masiva, cambió mucho el panorama. El estado tuvo que intervenir en la economia para impedir una catástrofe. Incluso en Estados Unidos, donde entre el final de la guerra europea (1919) y la crisis de 1929 la presencia del gobierno federal en la economia habia sido mínima, éste aumentó su papel para paliar los efectos de la crisis.

El estado fue aumentando su peso en las economias capitalistas a partir de la Segunda Guerra Mundial, por medio del establecimiento del estado del bienestar, las políticas keynesianas del manejo de la demanda agregada, y las medidas redistributivas hechas posibles por la misma expansión de la economía capitalista en los años cincuenta y sesenta. Así se fue creando una economía mixta en la que el estado, o sector público de la economia, aparecia, por lo menos en principio, como un poder compensador ("countervailing power") del de los oligopolios, que se estaban reconstituyendo y aumentando. Las políticas de corte social, la de pleno empleo, la co-gestión con los sindicatos, la legislación laboral, etc., incidieron en la elevación general del nivel de vida de los trabajadores (necesaria, por otra parte, en un sistema económico que produce masivamente bienes de consumo). Estas mejoras ocultaron, por algún tiempo, el proceso de concentración de empresas que se estaba dando por medio de la expansión mundial de los oligopolios norteamericanos y más tarde de los europeos.

Durante estos años de expansión y prosperidad (1945-1973) la teoría económica esta dominada por la síntesis neo-clásica, enseñada entre otros por el premio Nobel Paul A. Samuelson, que introdujo al estudio de la economia a muchas generaciones de estudiantes en todo el mundo. En ella se combinaba poco rigurosamente la microeconomia, que 
explicaba el comportamiento de los mercados mediante los modelos de competencia perfecta y monopolista, con la macroeconomia, que explicaba el comportamiento de los grandes agregados, como consumo, inversión gasto público, oferta monetaria, inflación, etc. La síntesis neoclásica reproduce en parte la maniobra de escamoteo y apología de los autores liberales de la segunda generación (Walras, Marshall, Pigou, etc.), los neo-clásicos, aunque reintroduce a la consideración de los economistas los problemas clásicos del crecimiento, la crisis, la acumulación y la redistribución en los análisis macroeconómicos. En conjunto, el pensamiento económico de los años dorados de la segunda mitad de este siglo ha puesto una conveniente sordina a las pretensiones ideológicas del gran capital (su larvado darwinismo social) y ha dado cabida a conceptos nuevos de solidaridad y responsabilidad social por parte de los agentes económicos.

\subsection{El resurgir de la Ideologia llamada neo-liberal}

Con la crisis de los años setenta viene la crisis del keynesianismo y del conjunto más o menos coherente de ideas que hacía aceptable a los diversos agentes sociales el papel que el estado tenía en la economia, asi como las medidas redistributivas y sociales. La crisis desata los instintos individualistas de los empresarios. Cuando el estado ya no puede regular el sistema, controlando la inflación y el ciclo económico, decrece la utilidad del estado para los negocios. Más aún, al aumentar los déficits fiscales y la necesidad de financiarlos ortodoxamente (es decir: captando ahorros del público), el estado se presenta como competidor del sector privado en el mercado de capitales. Con esta competencia se encarece el dinero, aumentan los tipos de interés y se reduce la inversión. De ahi sale el slogan: "El estado no es la solución; el estado es el problema".

De nuevo, como en el siglo XIX, para hacer retroceder al estado habrá que justificar las ventajas de su retiro. Pero ahora, esta justificación no se puede hacer en nombre de una competencia generalizada, porque los oligopolios dominan la organización industrial. Ni en nombre de una mano invisible, por que cuando las gentes están acostumbradas a ver y palpar la mano visible del estado del bienestar. Las circunstancias de las empresas son muy distintas y la opinión pública tiene otro nivel de información y de conciencia que en el siglo $X I X$. Para justificar el retiro del estado se monta una maniobra intelectual y políticá que abarca muchos frentes.

En primer lugar se demuestra a nivel teórico la imposibilidad de hacer una gestion macroeconómica acertada por parte del estado. Esta 
es la tesis central de la teoría de las expectativas racionales, que con gran lujo de matemáticas y aparato econométrico difunden por las facultades de economia los discipulos de Milton Friedman y otros gurús de la Universidad de Chicago (la universidad de Rockefeller). Según los teóricos de las expectativas racionales, el público, los agentes económicos individuales, disponen de la información suficiente como para anticipar las acciones del gobierno y anularlas con su comportamiento, si sienten que les puede perjudicar. La posibilidad de aplicar políticas basadas en la experiencia pasada e incorporada en los modelos econométricos que sirven para diseñar esas políticas, se queda reducida a los casos en que se sorprenda a los agentes. La conclusión práctica de esta escuela es que el estado debe ser mucho menos "militante" en el manejo de la economia. Vuelve la vieja prescripción friedmaniana de suprimir las intervenciones discrecionales de las autoridades y sustituirlas por reglas fijas (por ejemplo en el control de los activos líquidos).

Por otro lado se ponen de manifiesto los costos, presentes y futuros, del estado de bienestar, exagerados a consecuencia de la crisis que genera un número inaudito de desempleados, y de la evolución demográfica que va haciendo envejecer a la población. Los costos de la seguridad social y de la medicina social han aumentao en realidad a un ritmo mayor que en otras décadas, planteando un problema real $\rightarrow$ y no solo ideológico- de financiamiento en el futuro. Los elevados déficits de muchos estados se nutren de los gastos por este concepto. De ahí toman armas quienes pretenden reducir el papel del estado para proponer la alternativa de la privatización. Pero proponen privatizar, naturalmente, solo aquellas operaciones del sistema, como las jubilaciones y la asistencia médica, que pueden ser rentables a empresas privadas, sin disputar la gestión de las demás al estado.

Viene el ataque a los sindicatos de clase, que para efectos del análisis económico "científico", se conceptualizan como una magna distorsión del mercado de trabajo que, junto a otras, como el salario minimo, protección contra el despido, contratos permanentes, etc., se tienen que eliminar para permitir al mercado de trabajo que encuentre su equilibrio. Se insiste en la ineficiencia (por dis-economías de escala, generalmente) de las empresas públicas, muchas de las cuales han resultado del salvamento por el estado de empresas privadas en quiebra, y las que son rentables se pasan al sector privado para que las administre, resaltando el principio de la superioridad de la gestión privada y el motivo del lucro sobre la gestión pública.

* Se consagran las política exigidas por la supply-side economics (economía del lado de la oferta), que exaltan el papel de los inversores 
privados, la reducción de regulaciones y trabas a los negocios, la reducción de impuestos, y en general los cambios legales y administrativos que sean necesarios para fomentar la producción y las ganancias de las empresas. Se la contrapone a la economía de la demanda, que habia inspirado la gestión económica de las décadas anteriores, con fuerte intervención estatal.

Todas estas estrategias parciales de lo que, falsamente, se llama neo-liberalismo confluyen hacia lo que es la verdadera ideología del capitalismo de los oligopolios: el darwinismo social; el favorecer, cultivar y mimar, dar facilidades y recursos a los que más tienen, a los grandes empresarios, a los afamados banqueros, a los ricos, a los poderosos; sólo ellos pueden hacer funcionar el sistema. Sólo ellos nos pueden sacar de la crisis. Por eso privatizar es un imperativo; hay que ceder las mejores porciones del sistema de economía pública a los ciudadanos, pero sobre todo a los ciudadanos más ricos (caso de la privatización de Repsol), a los que realmente saben qué hacer con el dinero, ya que ellos tienen la solución de la crisis.

En ese estado de opinión se inscriben los gobiernos conservadores de Reagan y de la Señor aTatcher, que son el paradigma de todos los gobiernos capitalistas del mundo. Al cabo de una década de favorecer a los ricos, que ha sido en esencia la política de todos estos gobiernos, los resultados están ahi para que los evaluemos.

Los ricos, naturalmente, se han hecho más ricos. Este era el primer objetivo de la operación. Las ganancias de todo tipo de empresas medianamente llevadas han aumentado en estos últimos cinco años, a ritmos tan elevados como durante la década dorada de los sesenta. Como resultado del enriquecimiento de los ricos, el sistema ha funcionado mejor en una buena parte; se han creado millones de puestos de trabajo en los paises industrializados, aunque con un empleo mucho más precario que hace diez años y sin reponer todos los que se destruyeron durante la crisis. Unas empresas han comprado a otras, pagando a veces precios fabulosos (El holding financiero K.K.R. compró la. Reynolds Nabisco por 3 billones de pesetas) y el grado de concentración ha aumentado enormemente en sectores como la alimentación, las comunicaciones, la publicidad, etc. Se ha aumentado la pura especulación: de divisas, financiera, de suelo, viviendas, obras de arte, etc., lo que supone desvio de fondos de actividades estrictamente productivas.

Por su parte, los gobiernos han ido financiando déficits crecientes, contribuyendo a crear nuevos instrumentos de riqueza (pagarés, letras, etc.) y de especulación (seguros de prima única). Pero también ha 
aumentado de una manera alarmante el número de pobres. Junto a los nuevos ricos están surgiendo en todos los países los nuevos pobres, aquellos que aun trabajando no tienen dinero para comprar casa y frecuentemente ni para pagar un alquiler (el problema de los "homeless", sin hogar, en Estados Unidos es muy grave). Este es un tema que no hago más que tocar, por que ya se ha documentado y analizado en otras publicaciones de Cristianismo y Justicia.

Desde un punto de vista darwinista el aumento del número de pobres se podría interpretar que constituye los costos de la evolución. Para el bien de la especie es necesario que los mejor dotados prosperen y los peor dotados desaparezcan. Para el darwinismo social los nuevos pobres son el costó dolorosamente necesario para que los elegidos, los que tiran hacia adelante de la raza humana, estén cada dia en mejores condiciones para competir y crear riqueza. Los gobernantes no lo formulan así, tan descarnadamente, pero en la práctica es como si lo hicieran. La aparente resignación de la sociedad con las enormes bolsas de pobreza en medio de economías en pleno auge, parece indicar que lo consideran un mal necesario e inevitable.

Para concluir sólo nos queda ponderar cuán lejos estamos aquí y ahora del ingenuo pensamiento liberal del siglo $X \mid X, y$ de sus ideales de libertad, igualdad, fraternidad. Porque un mundo donde prive el darwinismo social es un mundo en que la libertad no cuenta porque todo está detemirnado; la igualdad es totalmente indeseable, porque el avance de la especie se basa en la diferencia de suertes y oportunidades, en la superioridad de algunos sobre los demás; y la fraternidad es una debilidad imperdonable, que no puede significar nada real en un mundo competitivo donde el hombre es para el hombre un lobo feroz.

\section{Notas}

1. Este ordenamiento jerárquico se da también al interior de las órdenes religiosas. Alli la caridad no lleva a la igualdad.

2. Tenemos abundantes testimonios de ello en la Biblia, y textos muy explícitos de Aristóteles, sobre la necesidad, de ley natural, de que la actividad económica esté regulada por las autoridades.

3. Adam Smith, "An Inquiry into de Nature and Causes of the" "Wealth of Nations." Book IV, Ch. I (re-edicion de Edwin Cannan), The University of Chicago Press. 1976. pp. 450-473. Se suele citar como "The Wealth of Nations" (La riqueza de las naciones).

4. El Rey sol hubiera adoptado la planificación central si la hubiera conocido en su tiempo.

5. Esta es la famosa y "única" cita de la mano invisible, que se ha empleado 
como para resumir toda la teoria de Smith y del liberalismo primitivo. Esta doctrina, sin embargo, contiene muchos y más importantes elementos, como luego veremos, que los contenidos en la metáfora de la mano invisible.

"Riqueza de las Naciones". Libro IV, cap. 2. En la versión inglesa de George J. Stigler. p. 477.

6. Adam Smith, "La riqueza de las Naciones", libro I, cap. 11, página 165.

7. John Stuart Mill, "Principles of Political Economy." Libro IV, cap. VII, par. 7 en la edición de Sir William Ashley, p. 763. El texto citado es en realidad contra los gremios, a los que considera de monopolio en el mercado de trabajo, pero lo que dice se puede aplicar también a las empresas.

8. David Ricardo, "The Principles of Political Economy and Taxation." Cap. XXV "On colonial trade" pág. 227 y ss. en la edición de Donald Winch.

9. Lord Robbins, "The Teory of economic Policy in English Classical Political Economy". 2nd. edition, MacMlllan, 1978, p. 26.

10. Adam Smith. "La Riqueza de las Naciones", Libro I. Cap. 8. En la edición de Edwin Cannan, pag. 88.

11. Robert Malthus, "Principies of Political Economy," primera edición, p. 184. Citado en el libro de Lord Robbins, p. 70, que tiene un capítulo con el título "The Condition of the People".

12. Es una tesis defendida poor el profesor norteamericano John K. Galbraith. "Economics and the Public Purpose."

13. Richard Hofstadter. "Great Issues in American History" Vol. III. Revised edition. vintage Books. 1982, pp. 87-89.

14. Richard Hofstadter, Loc. Cit., p. 84. 